Jeremy J. Ramsden

\title{
Nanotechnology for military applications
}

ABSTRACT. This paper examines some of the ways in which nanotechnology could be applied to enhance military ordnance, especially explosive devices propelled through the air, which makes any substitution that reduces weight of especial interest. Specific topics covered include propellants and explosives, optical materials, and materials for energy storage, heat management etc. The paper also discusses some of the practicabilities of procuring technology from the civilian market, and provides a useful update of the scheme of technology readiness levels used to classify new and emerging technologies, proposing nanotechnology availability levels for use specifically with nanotechnology.

Nanotechnology Perceptions 8 (2012) 99-131

Nonsubscribers: purchase individual article 